\title{
Study on the impact of tidal effects on water quality modelling of Juru River, Malaysia.
}

\begin{abstract}
This study on water quality modelling in Sungai Juru, Penang was undertaken as one of the most polluted rivers in Malaysia and is literally known as the 'dying river'. The research objectives are to assess the parameters that govern the amount of pollutants in the river and to identify appropriate measures to improve the river water quality. The main pollution sources are pig waste, discharge from agro-based industries, dumping of municipal and industrial waste. Due to its relatively flat bed gradient, Sungai Juru experienced tidal effect up to a distance of $13 \mathrm{~km}$ from the estuary. As a result, pollutants in the river are hardly discharged into the sea. This research on Dissolved Oxygen (DO) parameter has been carried out to develop a rehabilitation solution for Sungai Juru by using the numerical hydrodynamic modeling technique simulated by I-D Infoworks R.S software. The modeling involved two phases namely, development of a flow model followed by a water quality model. After the model has been successfully calibrated, the pollutant behaviour under various scenarios can be investigated. The hydraulic study of Sungai Juru revealed that the velocity at STJ02 ranging from -0.1 to $+0.12 \mathrm{~m} \mathrm{sec}-1$ during high and low tide, respectively. Based on this velocity, traveling time from S TJ02 (Sungai Juru) to STJ01 (Sungai Rambai) $(3.5 \mathrm{~km}$ ) is approximately between 9-10 h. The duration provides ample time for photosynthesis to occur resulting high DO ranging from $4-10 \mathrm{mg}$ at STJ01. The information is useful to determine pollution characteristics in Sungai Juru particularly related to tidal impacts. It is hoped that the modeling technique developed can be applied in other rivers in Malaysia which are subjected to tidal influences.
\end{abstract}

Keyword: Sungai Juru; Numerical modelling; Tidal effects; Water quality. 